\title{
“三圈层”协同育人：地方高校应用化学专业双创人才培养实践
}

谭明雄*, 覃其品, 黄国保, 陈渊, 张殊佳

玉林师范学院化学与食品科学学院, 广西玉林 537000

摘要: 在新产业和新经济背景下, 专业建设存在学生的价值取向、择业要求和实际有偏差, 人才培养不能适应新技 术、新产业发展需求等问题。本文以地方高校应用化学传统专业为例, 梳理了学生在不同发展阶段, 价值取向、能 力要求、资源需求, 支持载体和利益相关方的诉求, 将 “三圈理论” 引入 “双创人才” 培养, 构建以 “价值圈” 为 根本, 推动 “能力圈” 发展, 以 “支持圈” 为关键的 “三圈层” 协同育人模式, 形成 $1+1+1>3$ 的协同效应, 该模 式为地方高校的人才培养和专业发展提供参考。

关键词: 应用化学; 三圈理论; 人才培养

中图分类号: G64; O6

\section{Collaborative Education Based on "Three Circles": Practice of Cultivating Innovative and Entrepreneurial Talents for Applied Chemistry in Local Universities}

\author{
Mingxiong Tan *, Qipin Qin, Guobao Huang, Yuan Chen, Shujia Zhang \\ Department of Chemistry and Food Science, Yulin Normal University, Yulin 537000, Guangxi Province, China.
}

\begin{abstract}
With the Chinese economy moving toward new industries and new economies, some problems appear in talent training. The students' value orientation and work options cannot meet the actual expectation. The training of talents cannot meet the requirement of new technologies and new industries. The mode of cultivating innovative and entrepreneurial talents for applied chemistry in local universities is studied based on "Three Circles Theory". The collaborative education model of "Three Circles" have been produced after the completed analysis of students' value orientation, ability and resource requirements for different period, the support carrier and stakeholders. The "capability circle" is promoted with the "value circle" as the foundation and "support circle" as the key. The function of $1+1+1>3$ is reached. The mode will be useful as references for talent training and professional development of local universities.
\end{abstract}

Key Words: Applied chemistry; Three circles theory; Talent training

\section{1 引言}

2015年5月，国务院办公厅印发《关于深化高等学校创新创业教育改革的实施意见》，指出: “深 化高等学校创新创业教育改革, 是国家实施创新驱动发展战略、促进经济提质增效升级的迫切需要, 是推进高等教育综合改革、促进高校毕业生更高质量创业就业的重要举措 ${ }^{[1]}$ 。”随着经济发展、产业 结构不断升级, 新设备、新工艺、新技术、新产品不断涌现 ${ }^{[2]}$ 。在新产业背景下, 存在学生的价值取

收稿: 2021-06-15; 录用: 2021-07-05; 网络发表: 2021-09-07

“通讯作者, Email: tanmx00@163.com

基金资助: 2021年度广西高等教育本科教学改革工程重点项目(2021JGZ149); 玉林师范学院本科教学改革工程项目(2021XJJGYB03); 玉林师范 学院化学师范专业认证教改专题(2020ZYRZ01Z, 2020ZYRZ04A)；2020年广西一流本科专业/一流本科课程建设 
向、能力和择业要求和实际有偏差, 人才培养体系缺乏动态性、前瞻性和系统性等问题, 如何培养 具有创新创业能力的人才, 适应新技术、新产业发展需求, 是传统理工专业面临的一个亟待解决的 问题。

创新创业教育是一项系统的、动态的工程, 学生在不同成长阶段的价值取向、能力要求不同, 涉及的资源需求、支持载体、利益相关方的诉求, 随着产业的发展也有不同的要求。在供给侧改革、 产业升级转型的特殊时期, 人才培养体现动态性、条件性、多样性等特征 ${ }^{[3,4]}$ 。本文综合分析了学生 价值、能力和载体需求, 基于 “三圈层” 理论, 构建了 “三圈层” 协同育人模式, 以及实现路径。

\section{2 应用化学专业 “三圈层”协同育人实践探索}

我校是地方本科院校, 2003年设立应用化学本科专业, 围绕地方丰富的农产资源、矿产资源优 势, 依托生物化工广西重点学科, 广西农产资源化学与生物技术省级重点实验室学科优势, 着力培 养相关领域尤其是天然产物化工、食品药品分析技术的创新创业人才。2016年, 应用化学专业入选 广西高等教育创优项目 “应用化学自治区创新创业教育改革示范专业” 立项建设。针对新产业背景 下人才培养存在的问题, 我们走访了广西玉林地区、北部湾地区、广东珠三角等 30 多家企业, 开展 健康、医药、机械、有色金属、稀土金属等产业发展和人才规划课题研究, 构建了 “三圈层” 协同 育人模式，收到显著效果，2020年应用化学专业获批为广西一流本科专业。

\section{1 “三圈理论” 的应用背景}

“三圈理论” 是美国哈佛大学肯尼迪政府学院马克·莫尔和达奇·李奥教授, 在1995年创立的关于 公共政策或战略计划的分析工具。该理论强调了创建战略性计划需要遵循的三大要素: 价值、能力、 支持。第一是战略计划的目标是否具有价值取向, 能否创造公共价值, 即价值圈(value); 其次是战 略计划中必须要具备的能力, 包括达成目标的人力、素质、财力、物力等资源, 即能力圈(capability); 第三是计划执行需要获得的认同、支持、配合, 与社会环境形成的良好互动, 即支持圈(support), 这 三要素称之为 “三圈理论” (图1), 只有三圈相交, 该战略计划才可得到有效执行, 达到预期效果, 反之, 缺少任何一个圈, 计划都将无法实施 ${ }^{[5]}$ 。

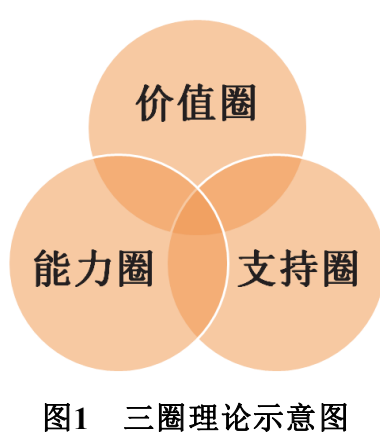

2002年, 我国引入 “三圈理论” 分析工具, 在公务员培训、党校教学、思想政治教育、乡村人 才培育、民族地区特殊教育等项目实施效果良好, 得到实际工作者和学术界广泛关注 ${ }^{[6-8]}$, 但是应用 在双创人才培养中, 国内属首次, 我们将 “三圈理论” 引入 “双创人才” 培养, 以 “价值圈” 为根 本, 推动 “能力圈” 发展, 以 “支持圈” 为关键, 三圈相互作用, 形成 $1+1+1>3$ 的协同效应。

\section{2 基于 “三圈理论” 的双创人才培养模式}

“三圈理论” 双创人才培养模式完全基于区域经济社会发展需求及学校的培养定位, 坚持以学 生为中心, 产出为导向。构建的价值圈和能力圈要素, 如价值圈的社会主义核心价值观、自我效能 感、自信心等, 以及能力圈的知识内化、经验生成、意识养成、孵化实践等, 这些都是毕业要求的 具体指标点, 也是培养目标中的分目标; 构建的双创人才成长模型, 包括课程体系、实践环节、项 
目训练等, 是毕业要求和培养目标达成的重要路径, 该培养模式为双创人才培养提出了明确方向和 要求。

\subsection{1 构建基于三圈层要素的双创人才成长模型}

梳理了学生创新创业发展各阶段的价值取向、能力要求、资源需求、支持载体, 利益相关方的 诉求, 考虑培育中的客观性、条件性、多样性等问题, 基于 “三圈层” 全要素, 形成双创人才成长 模型(图2)。

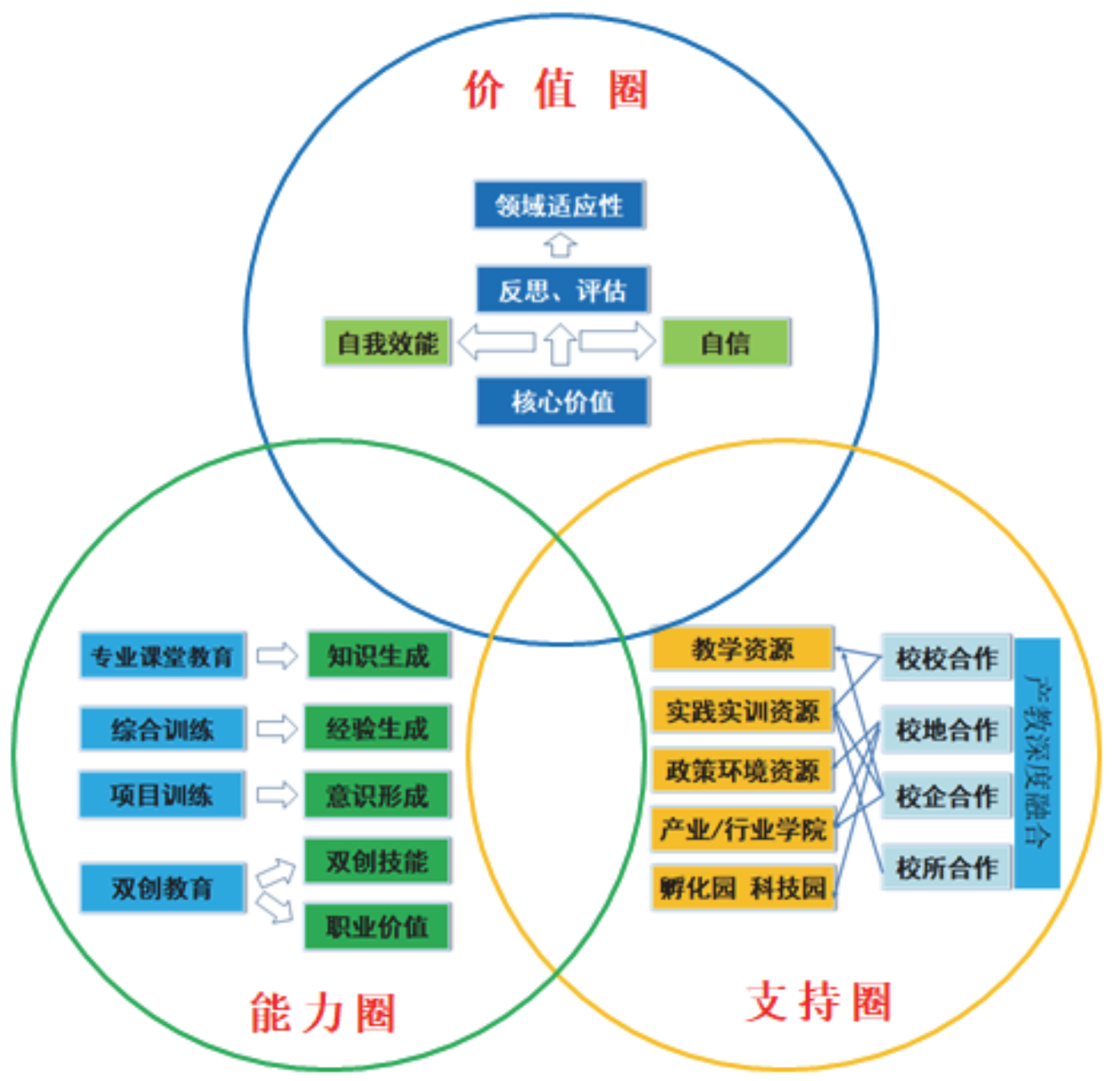

图2 双创人才成长模型

以 “价值圈”为根本：我校围绕习总书记关于高校 “为谁培养人，培养什么人”的总体论述， 以及立德树人的根本要求, 结合创新创业人才的内涵特征, 经过调查分析, 形成了包括自我效能、 自信心、领域适应性等要素的核心 “价值圈”。

以 “能力圈” 为重点: 双创人才的 “能力圈” 涉及双创技能和职业价值, 如知识生成、经验生 成、意识养成、孵化实践等要素。我校以实现能力圈要素为重点, 制定人才培养目标和规格, 管理 和评估机制, 为双创人才的培养提供可靠保障。

以 “支持圈” 为关键: 主要考虑培养方案所涉及的利益相关方的态度与意见, 人才培养过程中 的制约因素, 以及为实现这一过程的一整套管理和评估制度, 与之相匹配的政策环境、师资队伍、 教育资源、教育经费、课程资源等, 形成学校内部支持, 政府、行业、企业外部协同、相互作用的 “支持圈”。 


\subsection{2 构建以能力圈为导向的育人培养体系和层级推进路线}

我校以实现能力圈要素为重点, 以 “专业知识培养、基础技能培养、综合训练、项目训练” 为 主线, 制定双创人才培养课程体系(图3)。

新的课程体系摈弃了以往重基础、轻实践应用的思想, 以 “创新、应用” 为主线, 压缩基础课 程学分、课时, 新增专业方向课程(如药物分析、食品分析等)及创新创业类课程(如科技创新类、创 业类综合实践课程), 并将实践类课程学分增加至总学分的 $35 \%$, 使新的课程体系形成一个以能力圈 为导向的有机整体。

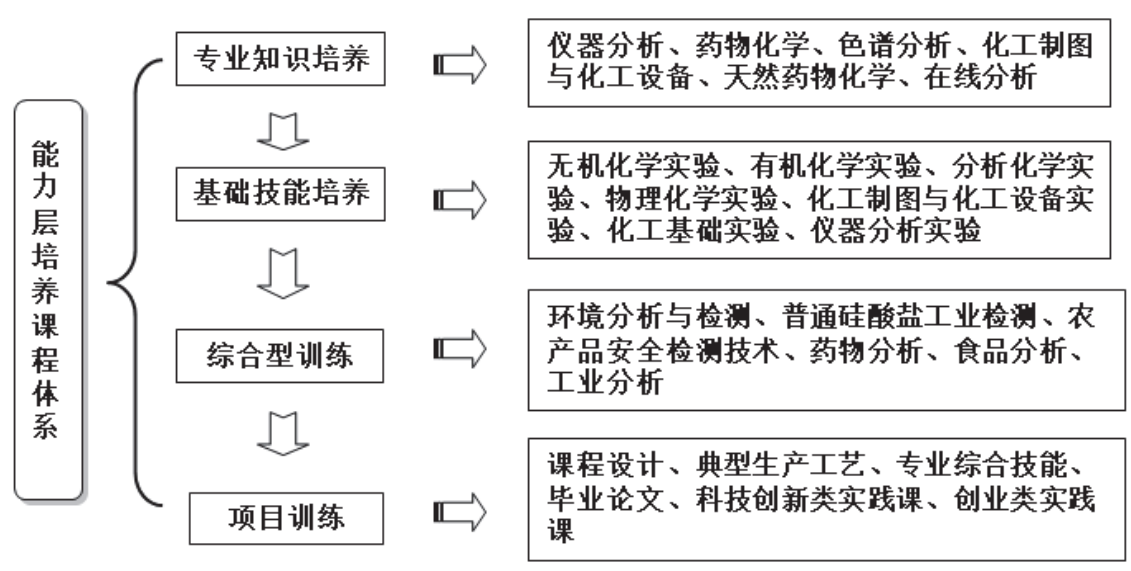

图3 能力圈培养课程体系

根据知识内化、经验生成、意识养成、孵化实践的逻辑要求, 制定学生不同阶段创新创业能力 培养的层级推进路线(图4), 促进人才培养高质量发展。

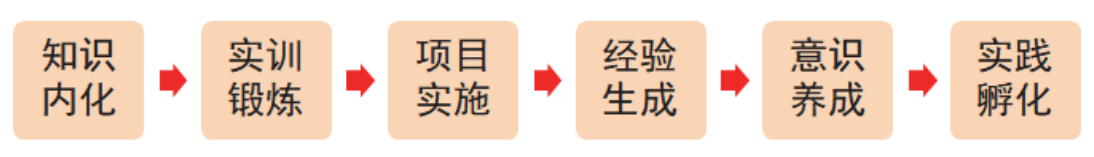

图4 能力培养的层级推进路线

通过国家 “挑战杯” “互联网+” “广西大学生化学化工创新成果设计” “教师专项科研课题研 究” 等实训锻炼和项目实施, 培育学生创新创业经验生成; 通过 “果酒加工标准化生产创新设计” “化工单元操作创新设计虚拟仿真实训” “大型仪器使用仿真实训” 等虚拟仿真创新实验, 培育学 生意识养成, 通过大学生孵化园、孵化器等创新创业载体, 提供实践孵化。

\subsection{3 把价值圈培养贯穿整个培养过程}

以价值圈要素为引导, 使理想信念教育由抽象变得更具体, 并将价值层要素和创新创业教育紧 密结合, 贯穿于学生教育教学全过程, 通过知识传授、实践育人、主题教育、综合育人等多渠道培 养学生自我效能感、自信心, 树立科学价值观、人生观, 培养社会适应性, 面对困难、面对任务, 有担当、能扛责任。

知识传授: 把知识、技能、态度、价值观的传授和内化, 体现在课程体系、评价体系、教学方 法、学习方式等培养全过程, 实现科学教育、思想教育与工程教育的有机融合。

实践育人: 鼓励学生走出课堂、走进社会、走进生活, 积极参加各种有益的社会实践活动, 了 解社会、认识国情、开拓视野, 在社会实践活动中磨练技能, 锻炼毅力、培养品格。 
主题教育：通过开展 “青年红色筑梦之旅” “青春·挑战·奋斗” “乡村振兴·服务社会” “创新创 业大赛” “创新创业成果主题展览” 等系列活动, 使学生了解国情民情; 通过创新创业实践与精准 扶贫、乡村振兴战略相融合, 厚植爱国情怀, 坚定理想信念, 强化学生的使命担当。

综合育人：学校重视搭建特色的育人平台。以 “家校共同体” “师生成长共同体” “创新创业 师生双选会” 为重要抓手, 构建了家校联动机制、师生联动机制, 教务处、学工处、学生会等部门 联动机制, 共同担责、协同履责, 提升人才培养的管理效益; 以时代楷模 “黄文秀” “黄大年” 榜 样为引领, 树立永远奋斗、甘于奉献的高尚情操。

\subsection{4 加强支持圈建设和夯实人才培养载体}

面向新产业需求，立足支持层要素，包括教学资源、实践实训资源、政策环境资源等，建立校 校、校企、校地、校所合作的协同育人新机制, 建立产业学院、孵化园、科技园、创客中心等人才 培养载体, 为学生创新创业提供支持服务。

学校建设的先进材料产业学院对接广西矿产资源产业链, 探索产业链、创新链、教育链有效衔 接机制, 探索 “人才共育、资源共享、专业共建、师资共培、课程共设、教材共编、就业共助、项 目共研、管理共治、质量共评” 人才培养机制。围绕功能陶瓷、纳米碳酸钙、纳米炭黑等先进无机 材料主产业, 校企共建集产、学、研、转、创、用于一体的人才培养创新平台, 提高学生实践和创 新能力, 强化学生职业胜任能力和持续发展能力, 打造人才培养、科学研究、技术创新、企业服务、 学生创业等功能于一体的示范性现代产业学院, 培养高素质应用型、创新型人才。

\section{3 结语与展望}

深化高等学校创新创业教育改革是我国新经济时代下高等教育改革的重要方向, 传统理工类专 业改革面临极大的挑战, 既要保留传统专业特色, 又要融于新的理论方法, 才能推陈出新、取得突 破, 促进专业发展。本文把 “三圈理论” 融入双创才培养, 把价值和能力要素形成动态模型, 综合 考虑企业技术需求、人才需求、学生成长的价值取向、能力要求、利益相关方的诉求, 有效解决传 统专业不能适应新产业需求; 把价值层贯穿人才培养全过程, 增强学生价值观、责任感, 培养地方 经济所需要的双创人才; 强调支持层载体作用, 解决了要素保障问题, 该模式为地方高校的人才培 养和专业发展规划提供参考。

\section{参 考 文 献}

[1] 李维红, 张奇涵, 李娜, 王颖霞, 裴坚. 大学化学, 2019, 34 (10), 1 .

[2] 吕洲, 朱倩倩, 李群, 王宗花, 毕赛. 大学化学, 2020, 35 (10), 87.

[3] 许雪棠, 周立亚, 段文贵. 大学化学, 2021, 36 (5), 2008070.

[4] 曹秋娥, 凌剑, 李菲, 周川华, 刘世熙, 王林. 大学化学, 2021, 36 (5), 2103001.

[5] 段宇波, 赵怡. 山西财经大学学报(高等教育版), 2010, 13 (1), 86.

[6] 曹俊德. 国家行政学院学报, 2010, No. 1, 37.

[7] 孙二军. 高教探索, 2019, No. 9, 119 .

[8] 张显. 中南林业科技大学学报(社会科学版), 2008, 2 (6), 23. 